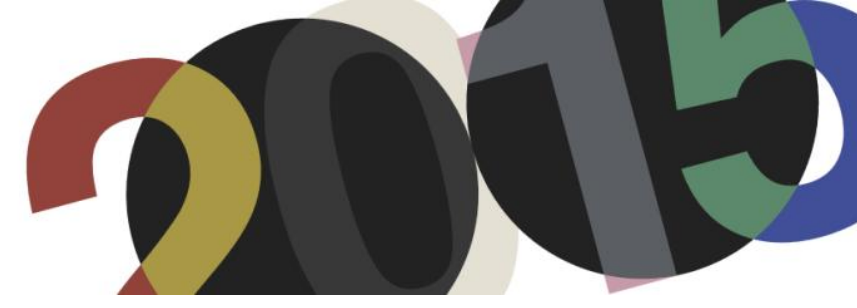

DOI: http://dx.doi.org/10.4995/LC2015.2015.631

\title{
Le Corbusier, el punto de partida de Juan Borchers
}

\author{
S. Maino Ansaldo
}

Universidad Técnica Federico Santa María

\begin{abstract}
Resumen: La figura de Le Corbusier ejerció una influencia sin contrapeso en la arquitectura moderna chilena, caracterizada salvo excepciones, por una adopción superficial y figurativa de sus ideas y formas. Entre estas excepciones está el singular caso del arquitecto Juan Borchers Fernández (1910-75) quien mediante sus agudas observaciones y lúcida crítica expone su adhesión mientras al mismo tiempo desmonta las contradicciones, los errores de interpretación y las falencias de las tesis lecorbuserianas. Para el análisis se utilizaron dos libros fundamentales (Vers une Architecture, 1923; Le Modulor, 1950) y dos artículos (L'angle droit, 1923; L'espace indicible, 1946) de Le Corbusier y las referencias a ellos en los libros, artículos, manuscritos, correspondencia y libretas de viajes de Borchers.
\end{abstract}

Abstract: Corbusier's influence in Chilean modern architecture is unique and it is characterized, with few exceptions, by superficial and figurative adoptions of his ideas and forms. Among these exceptions is the singular case of the architect Juan Borchers Fernández (1910-1975), whose acute observations and lucid review expose his adherence while at the same time they reveal the contradictions, misinterpretations and shortcomings about corbuserian's thesis. This analysis is based on two fundamental original books (Vers une Architecture, 1923; Le Modulor, 1950) and two articles (L'angle droit, 1923; L'espace indicible, 1946) by Le Corbusier and references to them in Borchers' books, articles, manuscripts, correspondence and travel journals.

Palabras clave: Chile, teoría de la arquitectura, plástica, escala.

Keywords: Chile, Architectural theory, plastic, scale.

\section{Introducción}

Juan Borchers Fernández (1910-1975) es uno de los pocos teóricos de la arquitectura moderna chilena con una línea de pensamiento original, condensando en un heterodoxo corpus teórico su adhesión a los planteamientos de la arquitectura moderna junto a una reinterpretación de la arquitectura clásica. Si bien, intelectualmente las raíces del pensamiento borchiano están en la cultura alemana, sus referentes de la disciplina son franceses e italianos, particularmente la figura sin contrapeso de Le Corbusier.

Al igual que Le Corbusier los viajes, la observación, la medición y la vivencia directa de las piezas fundamentales de la cultura arquitectónica occidental, fueron acciones centrales en la construcción de su teoría ${ }^{1}$. Borchers comienza a leer las obras de Le Corbusier una vez iniciados sus estudios de arquitectura en 1929, conociéndolo en su primer viaje a Europa en 1938, hecho que lo marca indeleblemente a lo largo de toda su trayectoria.

\footnotetext{
${ }^{1}$ Cf. MAINO, S. 2014. Pensar la distancia, pensar a distancia. Juan Borchers, viaje y obra (1947-1950). Doctor,
} Universidad Politécnica de Cataluña. 
"Conocí a Le Corbusier el año 38 en Paris a 27 años de su "Voyage Utile". Tenía entonces 51 años. Hablamos en varias ocasiones, bis a bis en la mesa de su taller."

Este es un momento particular para Le Corbusier; en la esquina del taller de rue Sevres están las maquetas del fallido proyecto para el concurso del Palacio del Soviets y el polémico del Palacio de las Naciones en Ginebra. Ese período marca para Borchers el Jugendwanderung ${ }^{3}$ de Le Corbusier, edad juvenil según la gradación de la evolución del espíritu humano expuesta por Leo Frobenius en su Paideuma ${ }^{4}$, momento caracterizado por una concepción del mundo casualmente ordenada, predominando lo intuitivo frente a la rigidez de la causalidad intelectiva. Época de los ideales en la cual el individuo es capaz de transformar la realidad en una unidad orgánica, mediante un acto creativo.

Entre los años '30 y '40 mientras se veían en la arquitectura chilena las primeras expresiones de un racionalismo epidérmico, Borchers proyecta una serie de viviendas y edificios teñidos por el influjo de las formas y los postulados lecorbuserianos. Posteriormente, en los 60 ' proyecta y construye junto a los dos miembros del Taller, Isidro Suarez y Jesús Bermejo, sus dos obras más conocidas, la Cooperativa Eléctrica de Chillán, 1960-1966 (fig.1) y La Casa Meneses, 1960-1970 (fig. 2), cuyas similitudes formales con la obra de Le Corbusier no dan lugar a dudas, cercanía corroborada en su correspondencia con Bermejo de la época: "el punto de partida es "VERS UNE ARCHITECTURE",". Esta cercanía al pensamiento lecorbuseriano no tiene que verse como una ciega militancia, sino un inicio sobre el cual, con el paso de los años, se fue consolidando un punto de vista propio e independiente de la arquitectura. Es así como podemos descubrir una serie de proximidades y distanciamiento con Le Corbusier y su aparato intelectual, de las cuales trataremos seis íntimamente ligadas entre ellas.

\footnotetext{
2 Borchers, Juan. "Prólogo". En Peñafiel, José Domingo: Le Corbusier y su Modulor. Director: Juan Borchers. Pontificia Universidad Católica de Chile, 1974. pp. 1-11.

${ }^{3}$ Caminar juvenil, espíritu juvenil.

${ }^{4}$ Frobenius, Leo. La Cultura Como Ser Viviente. Contornos De Una Doctrina Cultural Y Psicológica. Madrid: Espasa-Calpe, 1934.

${ }^{5}$ Borchers, Juan: Lo Plástico, Plástica, cosa General. Santiago: Ediciones Universidad Central, 2014. Publicación de: Carpeta Plástica, 1962/1966, FJB-D0539.
} 

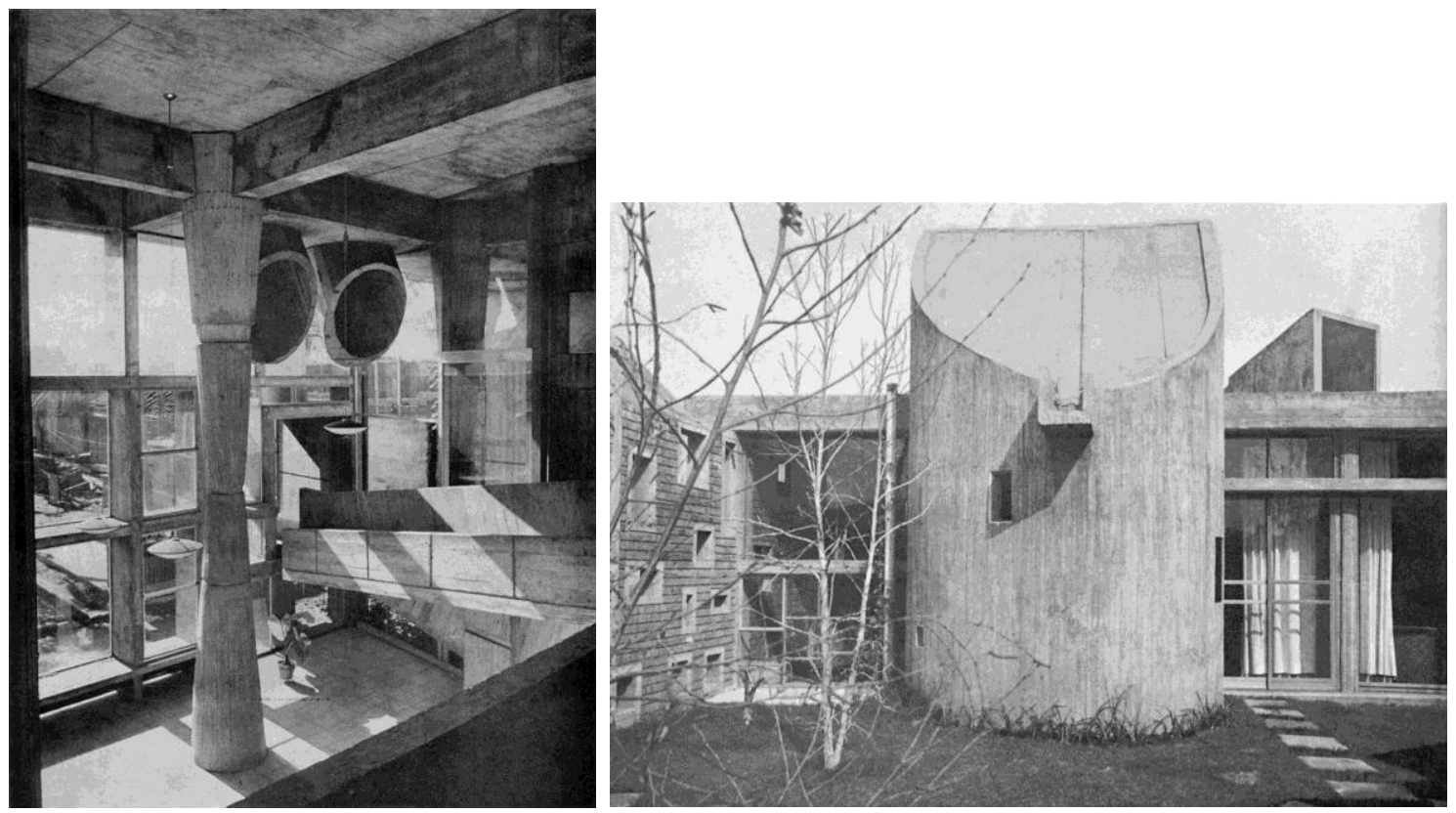

1. Interior del edificio Copelec. De fondo el brise soleil, separador entre el espacio interior y el patio posterior, a la derecha la rampa y al centro una de las columnas doble cónicas.

2. Exterior de la Casa Meneses.

\section{El hieratismo y las leyes del arte}

El período Purista de Le Corbusier está marcado por un fuerte ahistoricismo, desprendiendo las formas de su significado espacio-temporal, centrando su atención en la fisiología de las sensaciones y la especulación matemática. Uno de los conceptos estudiados por Le Corbusier y aplicado por Borchers es el hieratismo, cuya definición encontramos en el artículo L'Angle droit de Amedee Ozenfant y Le Corbusier en L'Esprit Nouveau' Ozenfant y Le Corbusier manifestan la existencia de las leyes axiales de la obra de arte, las cuales se pueden encontrar en el pasado; leyes que dan cuenta de una persistencia en nuestros organismos en la manera de percibir las obras de arte, una inmutabilidad fundamentada en la invariabilidad de nuestros órganos de los sentidos. El sistema postulado plantea que una obra de arte emociona y desencadena en nosotros un juego de recuerdos adquiridos y heredados mediante asociaciones automáticas. Dentro de este sistema, el hombre es un animal ordenador, al necesitar del orden para moverse dentro de la naturaleza, la cual en principio, tiene una apariencia caótica. Para esto el hombre ha elaborado sistemas de orden, en el entendido que estos sistemas le permiten explicar aquello que le rodea, con diferentes grados de distanciamiento de la realidad. La geometría es uno de esos sistemas, un sistema perfecto, sin contacto material con lo real, símbolo de perfección, irrealizable prácticamente 7 " El espíritu de orden ha creado signos, símbolos convencionales de ideas bien definidas que permiten construir la geometría y el lenguaje, hacer inteligibles las cosas, a uno mismo y a los demás, mediante abreviaciones eficaces" $"$. Los signos originados de esta manera son precisos, actuando según los autores, sobre

\footnotetext{
${ }^{6}$ Le Corbusier; Ozenfant, Amédée. "El Ángulo Recto". En Levene, Richard; Márquez Fernando (eds.): Acerca Del Purismo. Escritos 1918/1926. Madrid: El Croquis Editorial, 1993. p. 103-114.

${ }^{7}$ Ibíd., pp. 105.

${ }^{8}$ Ibíd., pp. 106.
} 
nuestros sentidos fisiológicamente, es decir, los procesos y las funciones producidas en los órganos por su interacción con el entorno son comprensibles mediante los principios de las ciencias exactas. De esta forma, como complemento a la componente de significado de un signo, se incorporan las leyes fisiológicas en su proceso de ideación y construcción. Los autores hacen la salvedad de que estos signos no son abstractos, ni convenciones de la escritura o las matemáticas, realizando de paso una crítica a la excesiva simplificación y depuración del neoplasticismo. Declarados los fundamentos de la relación entre hombre y arte, los autores inician la explicación del hieratismo:

"A falta de una palabra mejor, entendemos por hieratismo el estado del espiritu en que desemboca una civilización cuando, saliendo del período empírico, se vuelve consciente de algo que antes solamente sentía. Despojamos este término del sentido sagrado que la etimología le confiere, e incluso, si se lo dejáramos, tendríamos derecho a utilizarlo aquí, que la ciencia, antaño patrimonio de sacerdotes que la utilizaban religiosamente, ha cambiado de manos. Para evitar cualquier equívoco, hacemos laico el término hieratismo"”.

Definido el hieratismo, el paso siguiente es identificar sus medios o las formas de expresión:

"El espiritu hierático se expresa, pues, mediante equivalentes plásticos que proceden de una elección reflexionada de elementos cuyas propiedades fisiológicas y espirituales conoce exactamente.

Esos elementos están constituidos por objetos que tienen propiedades sensibles particulares y están dispuestos siguiendo ordenaciones que tienen efectos particulares especificos" ${ }^{, 10}$.

Para Ozenfant y Le Corbusier la fisiología tiene directa relación con comprender cómo vemos y qué figuras son legibles y reconocibles sin esfuerzo. El texto del artículo está acompañado por una serie de reproducciones de bajorrelieves egipcios, pudiéndose considerar el aporte de Borchers al estudio del hieratismo la incorporación de elementos tridimensionales: "Hay dos formas hieráticas: el cono y la pirámide, ahora bien pueden, reduciendo la zona de movimiento a ciertas directrices, conservarse inmóviles otras figuras. La esfera es inmóvil" ${ }^{, 1}$. Todas estas son formas cuya percepción no cambia con el desplazamiento del sujeto.

\section{El cilindro, la esfera y el cono, la herencia de Cezanne}

Conocido es el aforismo de Le Corbusier, "La arquitectura es el juego sabio, correcto y magnífico de los volúmenes bajo la luz ${ }^{\prime \prime 2}$ heredera para Borchers de la enigmática definición de los fundamentos de la pintura acuñada por Cézanne, expuesta en una carta a su amigo Emile Bernard ${ }^{13}$ :

"Trate la naturaleza a través del cilindro, de la esfera, del cono, todo ello situado en perspectiva, o sea que cada lado de un objeto, de un plano, se dirija hacia el punto central,"14.

\footnotetext{
${ }^{9}$ Ibíd., pp. 108-109.

${ }^{10}$ Ibíd., pp. 109.

${ }^{11}$ Borchers, Juan. Cuaderno de Egipto. 1948 (FJB-L22-044).

${ }^{12}$ Le Corbusier. Hacia Una Arquitectura. Barcelona: Ediciones Apóstrofe, 1998.

${ }^{13}$ La carpeta trabajo FJB-D1125 (1943-1947) de Borchers contiene las cartas enviadas por Cézanne a Emile Bernard, transcritas de L'Esprit Nouveau: Revue internationale d' esthétique (1920).

${ }^{14}$ Carta de Cézanne a Emile Bernard, Aix-en-Provence, 15 de abril de 1904. En Doran, Michael (ed.): Sobre Cézanne.

Conversaciones y testimonios. Barcelona: Gustavo Gili, 1980. pp. 51-52.
} 
Para Borchers los cubistas actuaron bajo la sugestión de los planteamientos de Cézanne considerándolo el fundador de la pintura moderna, a diferencia de Apollinaire que ve las últimas pinturas de Cézanne un resultado del cubismo, asignándole el título de padre del cubismo a Gustave Courbet ${ }^{15}$. Aunque hay variadas interpretaciones de la frase de Cézanne, según el historiador del arte Michael Doran el principio apunta a una "aprehensión de volúmenes por el estudio de sólidos simples" "16, tal como la entiende Le Corbusier, interpretación errada según Borchers. El error radica en que la atención de Cézanne no está puesta en los tres sólidos simples, sino en la superficie y la relación de colores entre ellas, nadie verá claramente estas tres figuras estereométricas en una tela de Cézanne ${ }^{17}$.

La profunda influencia que ejercen estas cartas de Cézanne sobre Borchers se reconocen en el principio gnoseológico de aproximación directa a la naturaleza, desconfiando de lo que ya se ha dicho sobre ella. Una mediación en esta aproximación ocultaría el sentido del original de dicha naturaleza proponiéndose Borchers como salida, practicar su estudio concreto y concienzudo, dibujar lo que veía y no lo que sabía.

La manera de abordar la descripción de un objeto, según Borchers, es una tríada jerarquizada, "objeto ideal”, "objeto geométrico" y "objeto sensible". Cada uno define en un plano diferente un mismo objeto real. El objeto sensible es capturado a través de los sentidos con todas las particularidades que definen su apariencia individual. El objeto geométrico surge de realizar una serie de generalizaciones del objeto sensible, con las cuales se logra comprender y reducir la variedad del objeto sensible a un número manejable de variables y elementos, mediante el número y la figura geométrica. El objeto ideal es una categoría que agrupa una serie de objetos sensibles bajo un modelo en el cual se explica la esencia del conjunto de objetos. Entre el objeto sensible y el objeto geométrico median los sentidos y entre el objeto geométrico y el objeto ideal media la mente. El objeto geométrico se capta siempre siendo "el intermediario entre la sensación y la idea" 18 . Borchers desea trabajar con ese margen abierto entre el objeto intelectualizado y el objeto real, buscando abordar mediante reglas las variaciones como algo constitutivo del ser del objeto.

La posición de Borchers se puede ver como una crítica al excesivo privilegio otorgado a la geometría en el proyecto y análisis de las obras por los arquitectos modernos, asignándole atribuciones que van más allá de ser un instrumento de composición y orden, transformando en una operación automática el reemplazo del objeto sensible (obra construida) por el objeto geométrico (trazado, dibujo). La simple construcción material del objeto geométrico reduce las posibilidades de expresión del objeto sensible. Si retomamos la primera definición en que ubicábamos al objeto geométrico como intermediario entre el ideal y el sensible, podremos entender que si aceptamos el remplazo del objeto geométrico por el objeto sensible, se transformaría un medio, es decir, la geometría, en un fin.

\footnotetext{
15 Apollinaire, Guillaume. Meditaciones Estéticas. Los Pintores Cubistas. Sobre La Pintura. Pintores Nuevos. Madrid: Antonio Machado Libros, 2001.

${ }^{16}$ Doran, op. cit., p. 247.

${ }^{17}$ Borchers, Juan. La Medición Como Substrato Del Fenómeno Arquitectural. Con Cantidades Crear Cualidades. Hogar y Arquitectura, Revista Bimestral de la Obra Sindical del Hogar, 1970, p. 26-39.

${ }^{18}$ Borchers, Juan. s/t, block. 1948 (FJB-D0590).
} 


\section{La arquitectura gótica y la Naturaleza. La Plástica}

"La arquitectura gótica no es, en su fundamento, una arquitectura en base a esferas, conos y cilindros. Sólo la nave expresa una forma simple, pero de una geometría compleja de segundo orden (cruceros de ojivas). Por esta razón, una catedral no es muy hermosa y buscamos en ella compensaciones de orden subjetivo, fuera de la plástica. Una catedral nos interesa como solución ingeniosa de un problema difícil, pero cuyos datos han sido mal colocados porque no proceden de las grandes formas primarias. La catedral no es una obra plástica; es un drama: la lucha contra la fuerza de gravedad, sensación de orden sentimental",19.

La crítica a la arquitectura gótica es evidente, su categorización como solución ingeniosa silencia su valor estético. Las catedrales góticas tanto francesas como españolas fueron objeto de intenso análisis e interpretación de Borchers, al principio en perfecta sintonía con el aserto de Le Corbusier, la estructura resistente fue el aspecto en el cual puso su atención, para luego dar paso al contexto próximo y las asociaciones con la naturaleza, el crecimiento y la transformación de las plantas, con el objetivo de extraer leyes universales de sus configuraciones. Si bien Le Corbusier y Borchers creen en las leyes de la naturaleza como proveedoras de un orden susceptible de ser aplicado en la arquitectura, el imaginario no es el mismo.

"Desde el punto de vista de la arquitectura, me coloco en el estado de espíritu del inventor de aviones. La lección del avión no está tanto en las formas creadas y, ante todo, hay que aprender a no ver al avión como un pájaro o una libélula, sino una máquina de volar; la lección del avión está en la lógica que ha presidido el enunciado del problema y ha conducido al triunfo de su realización "20.

Más adelante Le Corbusier escribe "desear volar como un pájaro, era plantear mal el problema",21 . Al igual que Le Corbusier, Borchers busca las leyes y no las figuras de la naturaleza, pero en vez de utilizar un paradigma de la modernidad como el avión, objeto construido por el hombre, basado en las leyes de la aerodinámica, Borchers se aboca a la observación de la flora y la fauna, determinando las leyes matemáticas y geométricas que contienen esas formas.

"La arquitectura es la primera manifestación del hombre que crea su universo, que lo crea a imagen de la naturaleza, sometiéndose a las leyes de la naturaleza, a las leyes que rigen nuestra naturaleza, nuestro universo. Las leyes de la gravedad, de la estática, de la dinámica, se imponen por la reducción al absurdo: sostener o derrumbarse ${ }^{, 22}$.

El imaginario maquinista no tuvo ecos en Borchers, lo cual no significaba que no hubiera experimentado los avances de la tecnología. Había cruzado el Atlántico en barco, había volado en avión desde Punta Arenas a Santiago y había disfrutado de la velocidad del automóvil en los terrenos abiertos de la pampa ${ }^{23}$. Podríamos suponer que ese imaginario maquinista abierto por Le Corbusier tal vez no tuvo eco en Borchers por provenir de un país poco industrializado, pero las razones para obviarlo son más profundas, tal como lo expone en Meta Arquitectura.

\footnotetext{
${ }^{19}$ Le Corbusier, op. cit., 1998. pp. 180.

${ }^{20}$ Le Corbusier, op. cit., 1998. pp. 85.

${ }^{21}$ Ibíd., pp. 89.

${ }^{22}$ Ibíd., pp. 56.

${ }^{23}$ Borchers, Juan. Meta Arquitectura. Santiago de Chile: Mathesis Ediciones, 1975. pp. 286.
} 
"Ese siglo, cuyo impulso fue dirigido a la construcción de máquinas, en el cual todo fue organizado: las organizaciones sofocaron el organismo. La era del mecanismo alcanzó sus ápices mundiales; cubrió todo el planeta. La cultura se identificó y significó lo mismo que orden y realización mecánica. Fue igualmente su fuerza como su ilusión: la mecanización y la uniformización del mundo' como finalidad, el último fin de la felicidad humana, olvidando que el mundo no es una organización sino un organismo „24.

La oposición entre la comprensión mecánica y orgánica ${ }^{25}$ del mundo fue tratada por Goethe y expuesta sucesivamente por Spengler ${ }^{26}$ y Frobenius. La concepción filosófica del mundo que nos rodea como un ser vivo, cambiante, alejó a Borchers del manifiesto pro ingenieril de Le Corbusier. La naturaleza se alza como el campo de búsqueda de las verdades trascendentes y de construcción de un imaginario de formas. Especial interés y resonancia tuvo la figura de Goethe y sus estudios de la naturaleza ${ }^{27}$ en Borchers, dadas las similitudes encontradas en sus métodos, fines y referencias. Goethe utiliza como método de observación de la naturaleza el registro de las características aparentes de las plantas, para luego mediante una inducción plantear conclusiones que tienen como fin alcanzar una relevancia universal, pese a lo limitado del campo de investigación. El concepto de metamorfosis propuesto por Goethe consiste en la transformación de diferentes partes de una totalidad, siendo cada una de ellas una derivación, es decir, una transición gradual de un elemento en otro. Bajo estos supuestos, Borchers ve cada una de las catedrales góticas como la concreción de las múltiples posibilidades de una idea que da lugar a un trazado, una manifestación sensible de un conjunto interno de variables limitadas. Cada una de las catedrales es una exteriorización de un orden, del mismo modo que una hoja lo es de una planta. Al igual que Le Corbusier, Borchers aplica los trazados regidos por proporciones, tanto a objetos naturales como a construidos, pero como una herramienta representativa de la diferenciación entre el objeto geométrico y el sensible (fig. 3). El estudio geométrico de los objetos naturales de configuración simple, tales como el huevo o la hoja, le permite reconocer las sutiles irregularidades de lo que aparenta ser similar, "dando lugar dentro de lo regular a la eterna variación”. Borchers lleva esta diferenciación al ámbito de la arquitectura, homologando el objeto sensible a la obra de arquitectura construida y el objeto geométrico al esquema de dicha obra, aclarando que el esquema no es la obra, sino que una generalización o reducción de un objeto concreto. El significado asignado a las irregularidades en las medidas aparentemente similares en templos y catedrales es una variable fundamental de la plasticidad en la arquitectura, contraponiéndose a los deseos de exactitud de la arquitectura moderna. Si para Le Corbusier "la plástica, es aquello que se ve y se mide con los ojos" reconociéndose lo plástico a través de la proporción o las "cantidades dispuestas en relaciones precisas" 28 , Borchers abre las puertas a una valoración de las diferencias.

\footnotetext{
${ }^{24}$ Ibíd., pp. 161.

${ }^{25}$ Acerca de la tradición mecanicista y organicista en arquitectura, cf. Rowe, Colin. The Architecture of Good Intentions : Towards a Possible Retrospect. London: Academy Editions, 1995.

${ }^{26}$ Spengler, Oswald. La Decadencia De Occidente. Bosquejo De Una Morfología De La Historia Universal. Madrid: Editorial Espasa Calpe, 1958.

${ }^{27}$ Cf. Goethe, Johann Wolfgang von. Teoría De La Naturaleza. Madrid: Editorial Tecnos, 1997.

${ }^{28}$ Ibíd.
} 


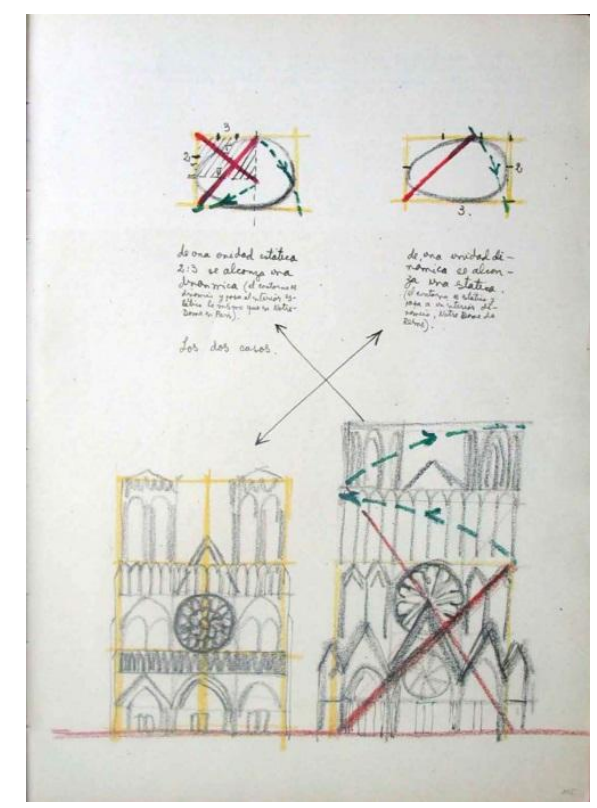

3. Trazado de las fachadas de las catedrales de Notre Dame de Reims y Notre Dame de París y su comparación con el trazado de un huevo. Cuaderno de Egipto, 1948. FJB-L22-004.

\section{El Partenón y su tiempo: sincronía o anacronía}

“Después de dos mil años, los que han visto el Partenón han sentido que había en él un momento decisivo de la arquitectura, 29 .

Las páginas dedicadas al Partenón en Hacia una Arquitectura, acompañadas por la fotografías de Frederic Boisonnas, describen y analizan al monumento paradigmático de la arquitectura moderna, valorándolo como un emblema de austeridad, pureza y decantación hacia lo más económico. Ese objeto celebre por las "sabias compensaciones", símbolo de la eliminación completa de las impurezas fruto de un proceso finalizado en el momento en que ya no era preciso quitar nada, es para Borchers la expresión de la muerte de una civilización.

Para Borchers, la arquitectura es sincronía, es decir, hay una coincidencia entre el objeto proyectado y la época en la cual es pensado. Por el contrario, la geometría que soporta a ese objeto proyectado es anacrónica, ya que no cobra sentido en la época, porque está fuera de su tiempo. Pero no toda obra por ser construida en su tiempo, es de su tiempo; una afirmación que se puede inducir de la observación realizada por Borchers acerca de la falta de armonía respecto de su tiempo del Partenón: "El primer templo griego era más armónico en el sentido viviente que el Partenón, tenía un poder de sincronismo superior al del Partenón, con el Partenón comienza el anacronismo" 30 . Una pregunta que surge de esta afirmación es: ¿Con que argumentos una obra valorada como una referencia irremplazable de orden y simetría, y paradigma de la arquitectura griega puede ser considerada "anacrónica"? Una primera pista surge del término "viviente", un eco del concepto acuñado por Goethe de "naturaleza viviente", aplicado por Spengler y Frobenius a sus interpretación de la cultura como si de un ser vivo se tratara. Dicho esto, no tan extraño resultará este juicio si utilizamos como elemento de contrastación el cuadro sinóptico de Spengler en el cual clasifica con personajes y hechos, cada una de las cinco etapas del ciclo de vida

\footnotetext{
${ }^{29}$ Le Corbusier, op. cit., 1998. pp. 180.

${ }^{30}$ Carta de J. Borchers a I. Suarez, 16/5/1949 (FJB-C0063).
} 
de las cuatro culturas relevantes de la Historia Universal (cultura egipcia, antigua, árabe y occidental), ubicando a la Acrópolis de Atenas y a su Partenón en la cuarta etapa de la Cultura Antigua, un período de "suma perfección de un lenguaje "perespiritualizado" de las formas", alejado del nacimiento y el perfeccionamiento de las formas de una cultura y previo al fin de un estilo. Spengler con el participio "perespiritualizado" hace alusión a un lenguaje en el cual el pasado se ha desvanecido al punto de tener una impresión inmóvil, intemporal, inmutable en su interior, una característica propia del estilo dórico, según él. Al igual que la geometría fruto de sucesivos procesos de abstracción, simplificación y decantación pasó a ser anacrónica, el Partenón como expresión representativa del pensamiento plástico griego, es el producto de un proceso similar de abstracción, simplificación y decantación en el cual, desde la posición del Partenón, los templos construidos con anterioridad pueden ser considerados ensayos. Así interpretado podemos concluir que en la medida que el producto de una cultura se depura, resolviendo sus problemas y dudas, pierde su condición viviente, orgánica y cambiante, transformándose en formula, una obra que no deja espacio al titubeo, a la vacilación, a la ambigüedad. Bajo este punto de vista la anacronía o sincronía no es interna a la obra, en el sentido de una cierta perfección en la aplicación de un sistema plástico, sino que tiene relación con el estado de desarrollo de una cultura.

\section{La escala en arquitectura (o la crítica al Modulor)}

Borchers conocía el sistema proporcional del Modulor en el año $1948^{31}$, posiblemente a través de la breve mención aparecida en las Oeuvre Complete 1938-1946 o en el artículo publicado por Matila Ghyka en la revista británica Architectural Review, en febrero de $1948^{32}$. El Modulor fue expuesto por primera vez el 25 de abril de 1947, en una conferencia dictada por Le Corbusier en el Congreso anual del American Designers Institute, conferencia publicada en la revista “Design” el mismo año ${ }^{33}$. En 1950 por fin verá la luz el libro bajo el título, Le Modulor ${ }^{34}$, cuyo objetivo primordial es la normalización de la construcción a nivel mundial, sin diferenciar economías o culturas. El sistema de medidas está fundado en la escala humana y la matemática, restringiendo el sistema proporcional a las medidas del cuerpo humano y un sistema de crecimiento reglado por la serie de Fibonacci. Al igual que en el principio de Protágoras, "el hombre es la medida de todas las cosas", el Modulor es la síntesis de un antropocentrismo y la simple constatación de que el hombre mide todos los objetos consigo mismo.

Le Corbusier, fuertemente impactado por la obra de Matyla Ghyka, construyó geométricamente el Modulor a partir de la altura estandarizada de un hombre $(1,83$ m.) y su división mediante la sección áurea. Borchers veía con escepticismo la validez universal que se le daba a la sección áurea como invariable estética sin un fundamento ni matemático, ni fisiológico ${ }^{35}$. El matemático norteamericano George Birkhoff también lo afirma en su libro La Media Estética ${ }^{36}$, estudiado por Borchers: "la sección aurea no es diferente a otras proporciones respecto de poseer propiedades geométricas simples." Con ello Borchers se desliga del tradicional tratamiento

\footnotetext{
${ }^{31}$ Borchers menciona el Modulor en su Cuaderno de Egipto. 1948 (FJB-L22-044). El libro lo compró en el mes de octubre de 1950 (FJB-C0170)

${ }^{32}$ Cf. Ghyka, Matila 1948, "Le Corbusier's Modular and the Concept of the Golden Mean", The Architectural Review $\mathrm{n}^{\circ} 103$, p. 39-42.

${ }^{33}$ Cf. Matteoni, Dario. La Ricerca Di Una Idea Di Proporzione: Il Modulor. Parametro n ${ }^{\circ}$ 85. Faenza: Faenza Editrice. 1980.

${ }^{34}$ Le Corbusier. Le Modulor : Essai Sur Une Mesure Harmonique a L'echelle Humaine Applicable Universellement a L'architecture Et a La Mécanique. Boulogne: Editions de l'architecture D'aujourd'hui, 1950.

${ }^{35}$ Borchers también estudio la obra del psicólogo alemán Gustav Fechner.

${ }^{36}$ Birkhoff, George David. Medida Estética. Rosario: Imprenta de la Universidad Nacional del Llitoral, 1945.
} 
estético de las proporciones y de las facultades simbólicas concedidas a la proporción aurea. Para él "las relaciones proporcionales no son bellas ni no bellas ${ }^{, 37}$.

Según Borchers, otra de las influencias que gesta el Modulor es la música serialista ${ }^{38}$, aunque dudando si Le Corbusier tenía una noción clara y definida del fenómeno musical o solo utilizaba las expresiones musicales de manera metafórica ${ }^{39}$. Esta duda se funda en la falta de especificación en la manera de relacionar las unidades de la serie como en la música serialista, en la cual la secuencia de notas no es aleatoria sino definida por reglas.

Por último, una debilidades del Modulor para Borchers es no declarar sus fuentes de información, alejándose de la tendencia de la investigación de indicar el origen, haciendo difícil ubicar su "invención" en el contexto de su tiempo y en la historia, catalogándola de "elucubración" validada por su talento y experiencia dimensional.

El punto de partida de Borchers para la determinación del concepto de escala en la arquitectura fueron los objetos que forman parte del medio natural, tales como animales, árboles y hombres; todos ellos unidades reconocibles cuyas medidas son referencias para nuestros sentidos: tacto o visión. A estos objetos los llamó portadores de escala, dada su capacidad de contener y transportar medidas estandarizadas. La correlación entre las medidas de este conjunto de objetos y el hombre, da pie a Borchers para adjetivar la escala de la cual son portadores, como escala humana ${ }^{40}$, un concepto que lo considera un suceso contemporáneo, de la mano de su principal divulgador, Le Corbusier.

La experiencia sensible de la escala es mediada por el órgano de la visión y su capacidad para percibir la lejanía, la cercanía y la progresión de la profundidad, junto a los mecanismos de corrección óptica que dan lugar a los fenómenos perspectivos. El concepto de fenómeno perspectivo hace alusión a la experiencia de la profundidad y como ella se hace presente a la conciencia del observador a través de los sentidos.

Descritos estos dos campos, los objetos portadores de escala humana y el de los fenómenos perspectivos, Borchers emplaza el fenómeno arquitectónico en la zona de mediación entre estos dos, denominándolo mundo intermediario (fig. 4). Con este gesto, aunó de manera expresa dos campos de difícil integración, argumentando además, la carencia de este nexo en las teorías contemporáneas de la arquitectura ${ }^{41}$, no así en el pasado. A diferencia de su propuesta, el sistema de proporciones de Le Corbusier es lineal, "más allá de $2 m$. 26 (última medida que dice del cuerpo humano), las medidas que aparecen en el Modulor son sólo extensión ilimitada donde ciertamente caben métricamente y análogas las iniciales. Realmente pudieron ser otras cualquiera" ${ }^{, 42}$.

Todo el largo proceso de experimentación y reflexión acerca de la escala en arquitectura se decanta en la obra póstuma de Juan Borchers Meta Arquitectura (1975), madurada junto a Jesús Bermejo, donde expone la serie

\footnotetext{
${ }^{37}$ de la Cruz, Rodrigo. Introducción. Revista ARS n 8 / 9. Número dedicado al Centenario del nacimiento de Le Corbusier, 1987. pp. 57-58.

${ }^{38}$ El arquitecto y músico Xenakis trabajó con Le Corbusier desde 1948 en adelante.

${ }^{39}$ Borchers, Juan. "Conclusión”. En Peñafiel, José Domingo: Le Corbusier y su Modulor. Director: Juan Borchers. Pontificia Universidad Católica de Chile, 1974. pp. 46-58.

${ }^{40}$ No se debe confundir medir con el cuerpo con la escala humana.

${ }^{41}$ Cf. Padovan, Richard. Proportion: science, philosophy, architecture. 1999; Irace, Cimoli. La Divina Proporzione. Atti del convegno (Milano, 27-29 settembre 1951). 2007.

${ }^{42}$ Borchers, op. cit., 1974.
} 
cúbica, el papel del número y la acción de medir en arquitectura desde el punto de vista perceptual, aritmético, geométrico, histórico, filosófico y musical. La serie cúbica es un sistema de control métrico y rítmico de la obra de arquitectura, compuesto por 22 valores divididos en 3 sistemas representativos de cambios en el fenómeno de la percepción (fig. 5). Aunque no profundizaremos aquí en esta similitud, Borchers evidencia en el Prefacio su deuda hacia la obra de Dom Hans van der Laan ${ }^{43}$, señalando que utiliza el sistema del monje holandés ampliándolo en ciertos ámbitos. La obra de van der Laan era y es absolutamente desconocida en Latinoamérica salvo contadas excepciones, siendo El Modulor (1950) de Le Corbusier el referente casi único en el ideario moderno acerca de las proporciones en arquitectura. Si la comparamos con el Modulor ${ }^{44}$, podremos ver que la serie cúbica ${ }^{45}$ está constituida por una sucesión de magnitudes de crecimiento más lento y el sistema de medidas aborda tanto la escala humana como aquella del objeto, quedando esta última bajo el control de la percepción.
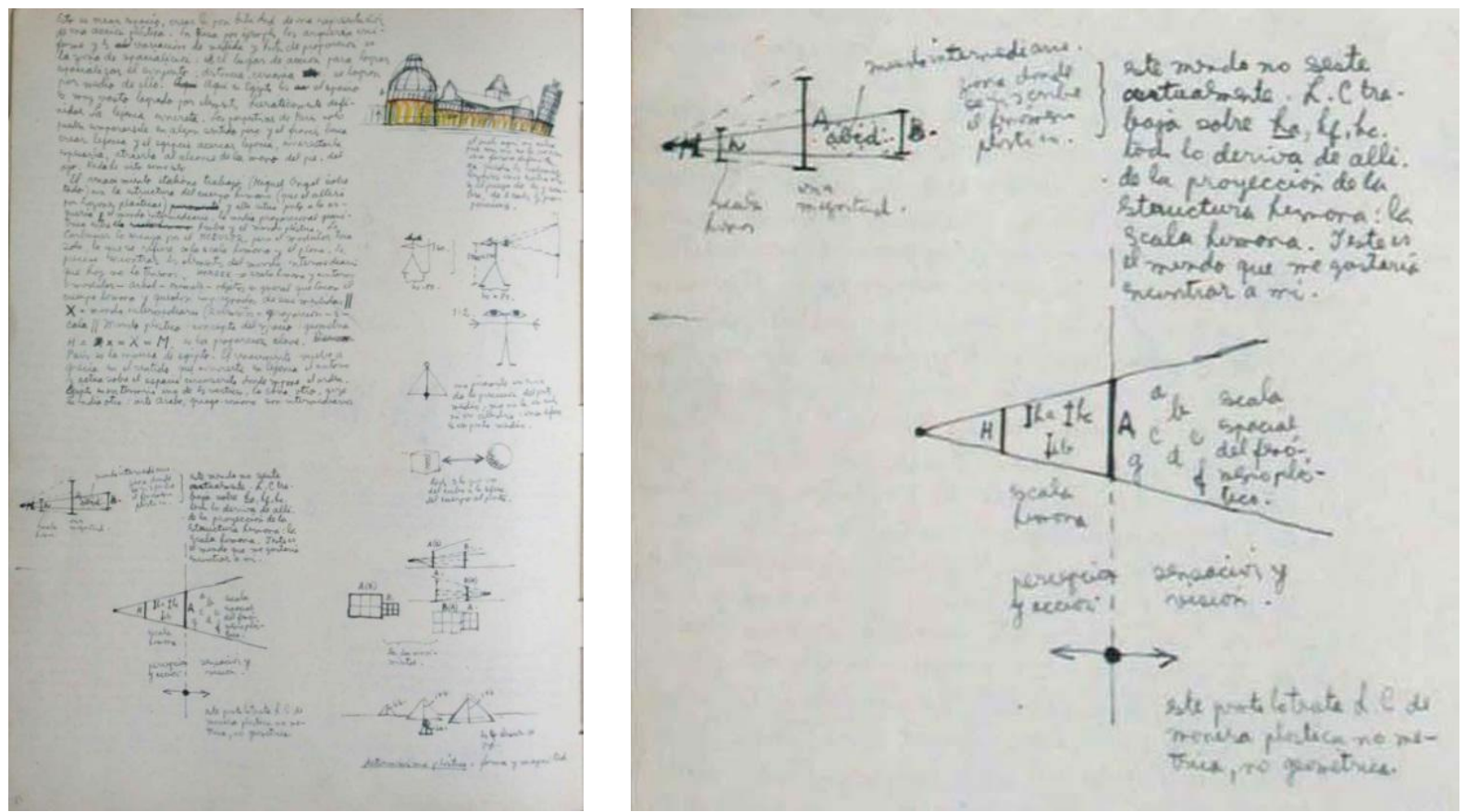

4.-4a. Cuaderno Egipto, noviembre de 1948. FJB-L22-044. "mundo intermedio / zona donde / se inscribe / el fenómeno / plástico / este mundo no existe / actualmente L. C: tra- / baja sobre ha, $h b, h c /$ todo lo deriva de allí / todo esto que va / de la proyección de la / estructura humana: la / escala humana. Y este / es el mundo que me / gustaría encontrar a mi."

\footnotetext{
${ }^{43}$ Laan, Hans van der. Le Nombre Plastique; Quinze Leçons Sur L'ordonnance Architectonique. Leiden: E.J. Brill, 1960.

${ }^{44}$ Le Corbusier planteó dos series a partir de la subdivisión mediante sección aurea de la altura de un hombre $(1,83 \mathrm{~m}$.) y la altura de un hombre con el brazo estirado (2,26 m.). La serie roja: 6, 9, 15, 24, 39, 63, 102, 165, 267, 432, 698, 1.130, (1.829), 2.959, 4.788, 7.747, 12.535, ... ; la serie azul: 11, 18, 30, 48, 78, 126, 204, 330, 534, 863, 1.397, (2.260), 3,658, $5.918,9.576,15.494,25.069, \ldots$ Entre paréntesis se marcan las dos alturas antes descritas.

${ }^{45}$ Los valores de la serie cúbica de Juan Borchers son: 4, 5, 7, 9, 12, 16, 21, (28), 37, 49, 65, 86, 114, 151, (200), 265, 351, 465, 616, 816, 1081, 1432. Entre paréntesis se marcan los dos cambios entre los tres campos. A diferencia del Modulor no son medidas sino que números.
} 


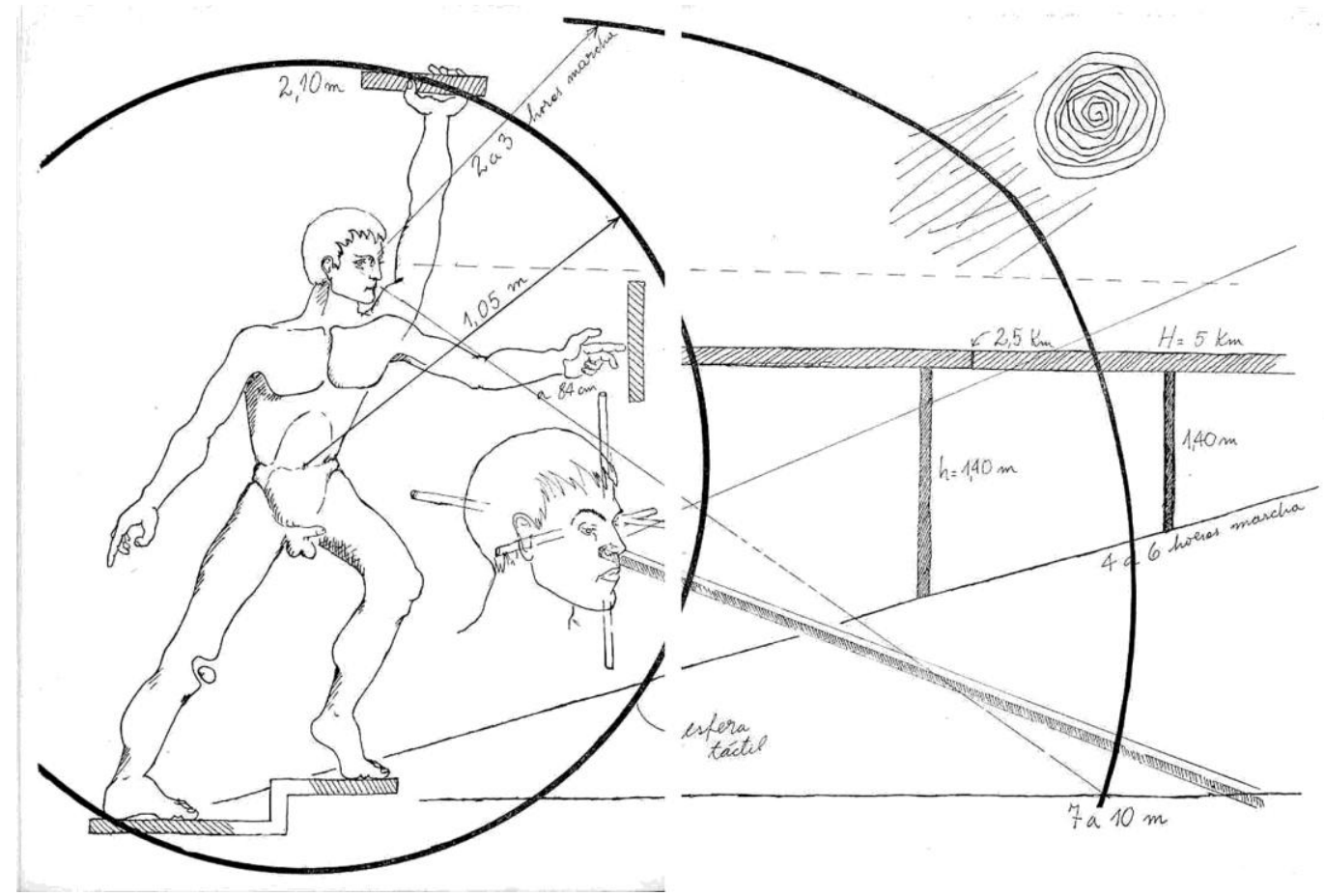

5. Los tres campos definidos por los cambios en la percepción: táctil, el visual o pictórico y el musical.

\section{7. "L'espace indicible"}

“"Estremecerse es lo más grande que puede hacer la humanidad.»Y aquel a quien el sino le haya negado este estremecimiento debe intentar descubrir los misterios; debe lanzarse sobre las cosas que imponen respeto, para despedazarlas, destruirlas y sacar de las ruinas su botín de ciencia. El afán de sistema es afán de matar lo viviente. En el sistema, las cosas vivas quedan fijadas, anquilosadas, atadas a la cadena de la lógica. El espíritu ha vencido cuando ha logrado llevar a buen término su empresa de petrificación ",46.

El Campo de los Milagros es una pieza fundamental en los estudios de Borchers, al igual que para Le Corbusier. En la descripción del proyecto para el Palacio del Soviets (1931) de Le Corbusier en las Oeuvre Complete 19291934, presentó una comparación entre el Campo de Pisa y sus componentes: el Duomo, el Baptisterio y la Torre, registrado a su paso por Pisa en tren el 4 de junio de 1934. Los dibujos del alzado del Palacio del Soviet y del Conjunto de Pisa aparecen en paralelo y ligados por el modo común en que se manifiestan sus reglas arquitectónicas desde la unidad al detalle, todo ello comprimido en una dimensión temporal y perceptiva, "tout a coup".

Pese a la instantaneidad de la percepción de Le Corbusier no debemos olvidar que la de 1934 fue su tercera visita a Pisa, habiendo sido cada una de las anteriores, una aproximación en diferentes escalas y una insistencia en lo mismo. Los dibujos de Le Corbusier son una cristalización y un testimonio de esas aproximaciones e insistencias. En su primera visita (1907), Jeanneret levantó minuciosamente los elementos arquitectónicos y precisó el rol de ellos en el ensamblaje de cada uno de los edificios. En su segunda visita (1911) se refirió

\footnotetext{
${ }^{46}$ Spengler, op. cit., pp. 25
} 
esencialmente a las relaciones entre los edificios del conjunto entendiendo el Campo como un total, resaltando las cualidades volumétricas. En el tercero (1934) dibujó el perfil del ensamble entre los edificios, una vista lejana que rememora una experiencia anterior, siendo utilizada como aclaración de su proyecto para el Palacio de los Soviets, el ensamblaje de edificios individuales y la autonomía relativa de cada una de las partes. Ese tiempo de decantación que cubre unos veintitrés años es comprimido en su frase tout a coup, momento en que la apariencia velada se transforma en una aparición.

Doce años después de la tercera visita a Pisa, Le Corbusier publicó $L$ ' espace indicible ${ }^{47}$ en la revista $L$ ' Architectured' Aujourd' hui ${ }^{48}$, articulo que a fines de la década del '50 transformó en un proyecto de libro que no se llegó a editar ${ }^{49}$. El artículo, compuesto paralelamente por textos e imágenes, navega entre sus proyectos de arquitectura y urbanismo no construidos, las pinturas y las esculturas. Amparándose en su extensa práctica en las artes mayores -arquitectura, escultura y pintura- aboga por su encuentro, esclareciendo la misión de cada una de ellas: "El urbanismo dispondrá, la arquitectura dará forma, la escultura y la pintura dirigirán las palabras selectas que son su razón de ser" ${ }^{, 50}$. Los proyectos utilizados son un acicate para la crítica y la reflexión, delimitando a través de lo ya realizado su búsqueda en el presente; búsqueda no libre de contradicciones y ambigüedades. En lo medular, para Le Corbusier toda obra de arte posee una parte intencionadamente oculta, un mundo verdadero que revela su significado solo a quien lo merece o a quien está dotado de la capacidad de síntesis necesaria para poder sentir y comprender el fenómeno. El espacio indecible se manifiesta en el momento de la anulación de los muros, los elementos concretos, pasando de lo contingente a lo trascendente. Los objetos ya no son vistos a través de un recorrido de un ojo atento, sino mediante su manifestación simultánea ${ }^{51}$. El espacio indecible es la cúspide de la emoción plástica. Podremos ver más adelante como esta caracterización coincide con la visión de golpe.

Entre su primer viaje a Europa en 1938 y 1950, Borchers dedica el trabajo más intenso y extenso al Campo de los Milagros la tercera de las cinco veces que lo visitó. El registro en las libretas ${ }^{52}$ de esta estancia se presenta dentro de un horizonte común de análisis de los elementos de un conjunto desde diferentes posiciones del observador, cuadro a cuadro, constatando las diferencias perceptuales que ellas implicaban. Borchers refleja en el objeto observado sus movimientos por el Campo; contrasta la perspectiva desde cada punto, con el fragmento de planta que le corresponde, destacando las superficies visibles, su perfil, sus zonas de sombra y las iluminadas (fig. 6). Los dibujos, expresión de la relación entre sujeto y objeto guardan similitudes con el dibujo de la portada del capítulo dedicado al plan en Vers une architecture (fig. 7), representando la Acrópolis de Atenas con una sección de la planta y la visión en perspectiva. El conjunto planta-perspectiva reproducido por Le Corbusier en estas páginas y otras posteriores, pertenecen a la Histoire de l'Architecture ${ }^{53}$ de Auguste $\mathrm{Choisy}^{54}$, quien

\footnotetext{
${ }^{47}$ Le Corbusier. El Espacio Inefable. Minerva. Revista del Círculo de Bellas Artes. IV época, n 2. 2006. pp. 6-11.

${ }^{48}$ Sabemos que Borchers leyó el articulo L' espace indicible de Le Corbusier, por su referencia en Meta Arquitectura: "Hacia 1945, fecha muy próxima al "Saggio" de Zevi, Le Corbusier había publicado su artículo, emotivo y espiritual, L' espace indicible." (Borchers, op. cit. 1975, p. 54).

${ }^{49}$ Cf. Smet, Catherine, Construcción suspendida: la obra editorial inacabada. En AAVV. Le Corbusier et le livre. Barcelona: COAC. 2005. pp. 164-199.

${ }^{50}$ Le Corbusier, op. cit., p. 11.

${ }^{51}$ Álvarez, Fernando. No dejar solas a las sombras. Algunos comentarios sobre "l' espace indicible" de Le Corbusier, DC PAPERS, Revista de Crítica y Teoría de la Arquitectura, $\mathrm{n}^{\circ}$ 1. 1998. pp. 57-77.

${ }^{52}$ Pisa queda registrada en dos libretas y un cuaderno: las libretas $n^{\circ} 7$ (FJB-L02-0007) y $\mathrm{n}^{\circ} 8$ (FJB-L02_0008) y el Cuaderno para Isidro (FJB-L21-0043).

${ }^{53}$ Choisy, Auguste. Histoire De L'architecture. Paris: Gauthier-Villars, 1899.
} 
dedica cuatro conjuntos planta-perspectiva ${ }^{55}$, las únicas de un libro profusamente ilustrado, para mostrar como en la Acrópolis de Atenas se produce el equilibrio de masas, seleccionando y privilegiando ciertos puntos de visión, desde donde los ángulos en los que se inscribe cada uno de los perfiles en planta de los diferentes cuerpos que componen el conjunto son simétricos. A diferencia de Choisy, Borchers fija aquellos momentos en que se establecen relaciones de continuidad entre los edificios. En su afán por comprender la realidad en la cual está inmerso, no toma el objeto arquitectónico como un cadáver el cual es objeto de disección, sino que lo aprecia como un cuerpo vivo del cual es necesario experimentar todas sus posibilidades. La obra de arquitectura no es únicamente una sumatoria de apariencias, sino también un fenómeno continuo posible de ser sentido y expresado unitariamente. Veinticinco años después saldrá a la luz como una imagen que rememora su experiencia:

"En el lapso, que debió de ser breve, pero que en mi imaginación me parece inmenso, apareció súbitamente el conjunto del Duomo de Pisa. Lo que duró esa percepción fugaz puedo pensarla como unos pocos minutos, si es que no más breve, un inmenso esqueleto desnudo hecho en mármol; una gran osamenta con el color de hueso" ${ }^{\text {"56. }}$.

La imagen que percibe Borchers de Pisa es sublime: la gran osamenta. Una asociación antropomórfica en la que subyace una estructura ligada a lo figurativo y un entramado denso de relaciones abstractas. Las posibilidades de lectura de esta imagen son varias. Primero está la asociación con el cuerpo humano, constituido por carne y huesos. La segunda, parafraseando a Goethe "en el esqueleto se ha conservado de manera segura y para la eternidad, el carácter exacto de toda forma" ${ }^{, 57}$. La tercera, el esqueleto se puede considerar como un complejo dimensional en el cual las partes están reguladas por reglas de proporción que constituyen un total. Y por último, parafraseando a Le Corbusier y su caracterización del proyecto para el Palacio del Soviets como un ser vivo compuestos por... "los tendones y los huesos de soporte y articulación, las capas musculares y las vísceras que contienen a las multitudes $" 58$.

La apariencia se transmuta en aparición justo en el momento en que toda la racionalidad acumulada es suspendida y reemplazada por una expresión, dejando de lado el pensamiento rigidizado por la normativa, abriéndolo al nombre poético, vital. La forma aparente o, como le dice Spengler, forma intuitiva, es la manera de estudiar la realidad en la antigüedad. Un paso más allá de esa forma intuitiva es su comprensión mediante las leyes invisibles que lo constituyen, aquello que no es aparente y que se plantea mediante la hipótesis metódica: "Pero la mirada profunda, que penetra en lo esencial, extrae de esa contingencia formas puras que, ocultas en lo más hondo, no se dejan descubrir fácilmente. Estas formas constituyen la base de todo el devenir humano"59.

\footnotetext{
${ }^{54}$ Cf. Banham, Reyner. Teoría Y Diseño En La Primera Era De La Máquina. Barcelona: Ediciones Paidos. 1985; Hidalgo, Germán. Los ecos de la planta: Organización lógica de las sensaciones espaciales, ARQ n 58. 2004. p.68-71.

${ }^{55}$ Esta secuencia descrita por Choisy es reproducida por Sergei Eisenstein en su artículo Montaje y Arquitectura (1938) en el que trata, precisamente acerca de la representación de un fenómeno y su multidimensionalidad. Le Corbusier conoció a Eisenstein en Moscú en 1928, declarando en una entrevista a un periodista moscovita: "Arquitectura y cine son las únicas artes de nuestro tiempo. En mi propio trabajo yo he pensado como Eisenstein lo hace en sus películas.” (WEBER, N. F. 2008. Le Corbusier : a life, New York, Alfred A. Knopf). Contemporáneamente, Borchers comparó algunas de las películas de Eisenstein con obras de arquitectura por sus características geométricas.

${ }^{56}$ Borchers, op. cit., 1975, p. 245.

${ }^{57}$ Goethe, Johann Wolfgang von. Teoría De La Naturaleza. Madrid: Editorial Tecnos, 1997.

${ }^{58}$ Le Corbusier, op. cit., 2006. pp. 8.

${ }^{59}$ Spengler, op. cit., 1958, pp. 150.
} 
Podría resultar contradictorio que en ambos casos esta visión de golpe -Borchers lo denomina lapso breve y percepción fugaz- tuviera un tiempo tan largo para salir a la luz, pero resulta evidente que la primera intuición, indeleble e indecible en un principio, es develada tras las diversas aproximaciones al objeto arquitectónico, logrando en definitiva que esa aparición inicial sea comprendida, cercada, por intermedio de la apariencia, por la representación intencionada de la realidad.

"Esa primera sensación perduraría siempre, como la base soterrada que los trabajos, más analíticos y prolijos posteriores, no sólo no la borra, sino que además, la sostiene como si fuera su esencia fundamental "60.

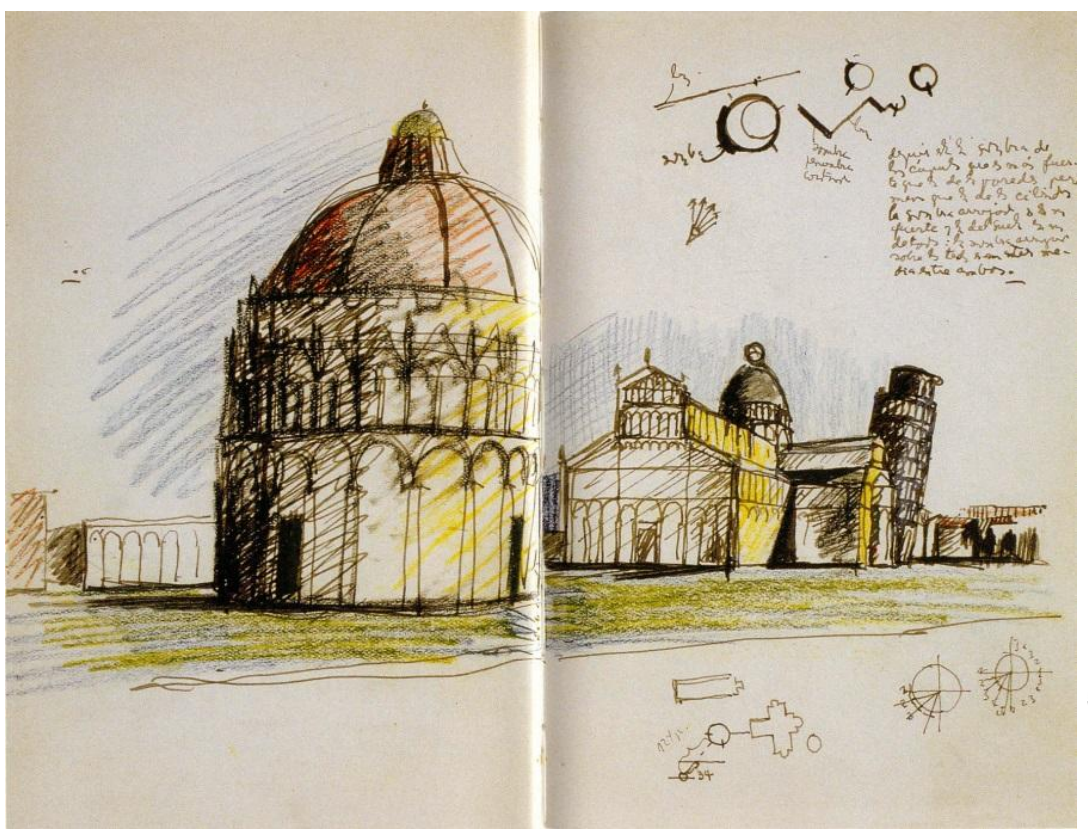

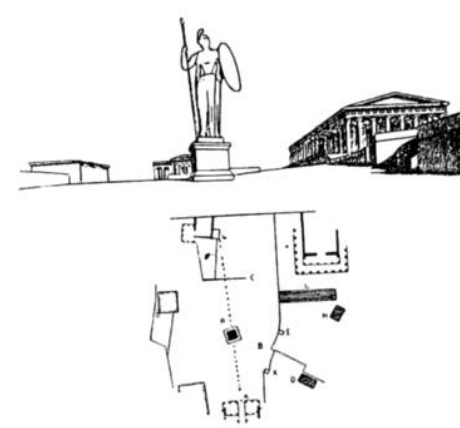

TRES ADVERTENCIAS A LOS SEÑORES ARQUITECTOS III EL PLAN

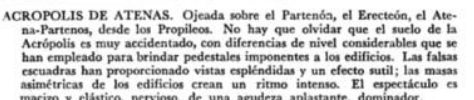

6. Dibujos del Campo de los Milagros, Pisa, Libreta 7, entre el 1 y el 4 de Octubre de 1948 (FJB-L02-0007).

7. Portada de la tercera advertencia dirigida a los arquitectos, incluida en Hacia una arquitectura, Le Corbusier (Le Corbusier, 1998, p. 31)

\section{Conclusión}

Le Corbusier se alza como el referente intelectual de la arquitectura contemporánea de Borchers, punto de partida para iniciar la construcción de su propia teoría, tejida con asociaciones del campo de la filosofía, la matemática, las ciencias naturales, la historia, la poesía, la música y la antropología.

Las leyes fisiológicas del arte son un campo de estudio común, ampliado por Borchers con las investigaciones de la psicología experimental y las certidumbres obtenidas por el conocimiento de las relaciones matemáticas entre estímulo y sensación, dotando la construcción de la serie cúbica de un rigor científico del cual adolecía el Modulor.

\footnotetext{
${ }^{60}$ Borchers, op. cit., 1975, pp. 245.
} 
Si bien, ambos buscan fundamentar su obra en leyes de validez universal, el imaginario asociado se enmarca en dos tradiciones opuestas de la arquitectura: la mecánica y la orgánica. Le Corbusier elogia la exactitud moderna de las máquinas y las leyes que las gobiernan, en cambio Borchers, seducido por la naturaleza viviente, por los organismos, centraliza su atención en las diferencias y transformaciones de las configuraciones de un mismo tipo, en cuanto a ser expresión de vida. Si para Le Corbusier la Naturaleza es una analogía discursiva en sus planteamientos arquitectónicos, para Borchers es la fuente de las reglas de control de la obra de arquitectura.

Todas estas diferencias y similitudes expresan la relevancia del maestro para Borchers, sin duda el mayor de sus contemporáneos, sin perder de vista la necesaria reformulación de sus principios.

En 1965 Borchers, durante el ciclo de diecisiete conferencias (escritos-lecturas) parcialmente publicados en Institución Arquitectónica en 1968, relata el silencio que siguió a la muerte del maestro:

“Acababa de leer el decimotercero escrito-lectura; poco después, horas, moría Le Corbusier, y esto fue causa por lo que dejé pasar dos meses antes de reiniciar las lecturas. "61

\section{Agradecimientos}

Agradecimientos al Archivo de Originales Sergio Larraín García-Moreno de la Facultad de Arquitectura, Diseño y Estudios Urbanos de la Pontificia Universidad Católica de Chile, por su colaboración en la elaboración de este artículo.

\section{Procedencia de las imágenes}

Imagen 1 y 2 Borchers, J. 1970; Imagen 3, 4 y 6 Fondo Documental Juan Borchers F., Archivo de Originales SLGM. FADEU. Pontificia Universidad Católica de Chile; Imagen 5 Borchers, J. 1975; Imagen. 7 Le Corbusier 1998.

\section{Referencias bibliográficas}

Álvarez, Fernando. No dejar solas a las sombras. Algunos comentarios sobre "l' espace indicible" de Le Corbusier, DC PAPERS, Revista de Crítica y Teoría de la Arquitectura, n 1. 1998. pp. 57-77.

Apollinaire, Guillaume. Meditaciones Estéticas. Los Pintores Cubistas. Sobre La Pintura. Pintores Nuevos. Madrid: Antonio Machado Libros, 2001. Traducción de: Les Peintres Cubistes :(Méditations Esthétiques). Paris: Eugène Figuière et Cie, 1913.

Borchers, Juan. Institución Arquitectónica. Santiago de Chile: Editorial Andrés Bello, 1968.

Borchers, Juan. La Medición Como Substrato Del Fenómeno Arquitectural. Con Cantidades Crear Cualidades. Hogar y Arquitectura, Revista Bimestral de la Obra Sindical del Hogar, 1970, p. 26-39.

Borchers, Juan. "Prólogo"; "Conclusión”. En Peñafiel, José Domingo: Le Corbusier y su Modulor. Director: Juan Borchers. Pontificia Universidad Católica de Chile, 1974. pp. 1-11; pp. 46-58.

Borchers, Juan. Meta Arquitectura. Santiago de Chile: Mathesis Ediciones, 1975.

\footnotetext{
${ }^{61}$ Borchers, Juan. Institución Arquitectónica. Santiago de Chile: Editorial Andrés Bello, 1968.
} 
Borchers, Juan: Lo Plástico, Plástica, cosa General. Santiago: Ediciones Universidad Central, 2014. Publicación de: Carpeta Plástica, 1962/1966, FJB-D0539.

Choisy, Auguste. Histoire De L'architecture. Paris: Gauthier-Villars, 1899.

de la Cruz, Rodrigo. Introducción. Revista ARS n 8 / 9. Número dedicado al Centenario del nacimiento de Le Corbusier, 1987. pp. 57-58.

Doran, Michael (ed.): Sobre Cézanne. Conversaciones y testimonios. Barcelona: Gustavo Gili, 1980. pp. 51-52.

Frobenius, Leo. La Cultura Como Ser Viviente. Contornos de una Doctrina Cultural y Psicológica. Madrid: Espasa-Calpe, 1934. Traducido del alemán: Paideuma : Umrisse Einer Kultur- Und Seelenlehre. München: C.H. Beck'sche Verl, 1921.

Goethe, Johann Wolfgang von. Teoría De La Naturaleza. Madrid: Editorial Tecnos, 1997.

Le Corbusier. Hacia Una Arquitectura. Barcelona: Ediciones Apóstrofe, 1998. Traducción al castellano de: 1923. Vers une architecture, Paris, Saugnier.

Le Corbusier; Ozenfant, Amédée. "El Ángulo Recto". En Levene, Richard; Márquez Fernando (eds.): Acerca Del Purismo. Escritos 1918/1926. Madrid: El Croquis Editorial, 1993. p. 103-114. Publicación del artículo: L'angle droit, L’Esprit Nouveau n¹8, 1923.

Le Corbusier. El Espacio Inefable. Minerva. Revista del Círculo de Bellas Artes. IV época, n 2. 2006. pp. 6-11. Traducción al castellano de: L'espace indicible. L'Architecture d'Aujord'hui. 1946. pp. 10.

Le Corbusier. Le Modulor : Essai Sur Une Mesure Harmonique a L'echelle Humaine Applicable Universellement a L'architecture Et a La Mécanique. Boulogne: Editions de l'architecture D'aujourd'hui, 1950.

Spengler, Oswald. La Decadencia de Occidente. Bosquejo de una Morfología de la Historia Universal. Madrid: Editorial Espasa Calpe, 1958. Traducción al castellano de Der Untergang Des Abendlandes Umrisse Einer Morphologie Der Weltgeschichte. Viena - Leipzig: Wilhelm Braumüller, 1918-22.

\section{Fuentes documentales}

Borchers, Juan. s/t, block. 1948 (FJB-D0590).

Carta de J. Borchers a I. Suarez, 16/5/1949 (FJB-C0063).

Borchers, Juan. Cuaderno de Egipto. 1948 (FJB-L22-044). 